\title{
Pericardial extramedullary haemopoiesis in chronic myelomonocytic leukaemia
}

\author{
C R Bradford, S R Smith, J P Wallis
}

\begin{abstract}
Chronic myelomonocytic leukaemia (CMML) is a myelodysplastic syndrome with a diverse clinical spectrum. A case of a 60 year old man with CMML who developed cardiac tamponade is reported. Cytological examination of the pericardial effusion fluid showed extramedullary haemopoeisis. Serous effusions are well recognised in association with this disease, but this seems to be the first reported case of extramedullary haemopoiesis resulting in a pericardial effusion in a patient with CMML.
\end{abstract}

(F Clin Pathol 1993;46:674-675)

Chronic myelomonocytic leukaemia (CMML) is a myelodysplastic syndrome characterised by a peripheral blood monocytosis $(>1 \times$ $10^{9} / 1$ ) and trilineage dysplasia. ${ }^{1}$ It may be associated with splenomegaly and lymphadenopathy. ${ }^{23}$ Less common associations are those of serous effusion ${ }^{4}$ and skin infiltration. ${ }^{5}$

Department of

Haematology,

Freeman Hospital,

Newcastle upon Tyne

NE7 7DN

C R Bradford

$S$ R Smith

J P Wallis

Correspondence to:

DrJWallis

Accepted for publication 27 November 1992

\section{Case report}

A 60 year old man was admitted to hospital for an inguinal hernia repair and found to have splenomegaly. A full blood count showed a haemoglobin concentration of $122 \mathrm{~g} / \mathrm{l}$, a white cell count of $16.4 \times 10^{9} / 1$ (neutrophils 54\%, lymphocytes $10 \%$, monocytes $28 \%$, eosinophils $1 \%$, basophils $4 \%$ and

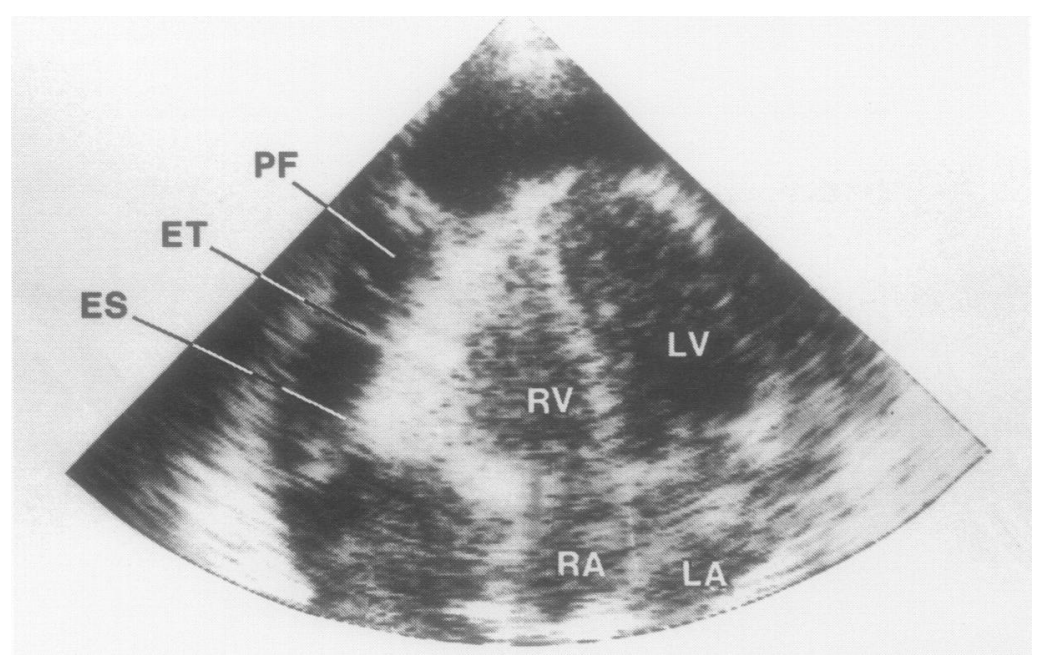

Figure 1 Longitudinal echocardiographic view of heart showing the pericardial fluid $(P F)$, compromised left atrium ( $L A)$, left ventricle ( $L V)$, right ventricle $(R V)$, irregularities on the epicardial surfaces (ES), and bands of echogenic tissue (ET) in the pericardial space. myelocytes $3 \%$ ), and a platelet count of $165 \times 10^{9} / 1$.

Coagulation screen was normal. An abdominal ultrasound scan showed that his spleen was greatly enlarged as were epigastric, portal, and para-aortic lymph nodes. The liver was normal and no ascites was seen. A chest $x$ ray picture was normal. Bone marrow aspirate was hypercellular with active myelopoiesis (78\%). Monocytes accounted for $4 \%$ of all nucleated cells and there was no excess of blasts.

Erythropoiesis showed minor dysplastic change and megakaryocytes were normal. A trephine biopsy specimen was hypercellular with loss of all fat spaces. Aggregates of large immature cells were noted. Reticulin was increased. Chromosomal analysis showed a normal $46 \mathrm{XY}$ male karyotype. Serum lysozyme was increased to $190 \mu \mathrm{g} / \mathrm{ml}$ (normal range $0-15 \mu \mathrm{g} / \mathrm{ml}$ ). Renal and hepatic function tests were normal. Chronic myelomonocytic leukaemia was diagnosed.

At review three weeks later a supraventricular tachycardia was noted. This reverted spontaneously to sinus rhythmn on admission to hospital. He was discharged with a prescription for Digoxin $0.25 \mathrm{mg}$ daily. Two weeks later he was admitted as an emergency with severe dyspnoea. Examination showed signs consistent with cardiac tamponade.

A full blood count showed that his leukaemia had progressed (haemoglobin 100 $\mathrm{g} / \mathrm{l}$, a white cell count of $50.2 \times 10^{9} / 1$ (neutrophils $74 \%$, lymphocytes $2 \%$, monocytes $20 \%$, basophils $1 \%$, myelocytes $3 \%$ ), and a platelet count of $217 \times 10^{9} / 1$. An echocardiogram showed a pericardial effusion with severely compromised cardiac function, pericardial thickening, and epicardial irregularities (fig 1). The effusion was drained under ultrasound control of 1.2 litres of fluid with immediate symptomatic relief. The pericardial fluid had a haemoglobin concentration of

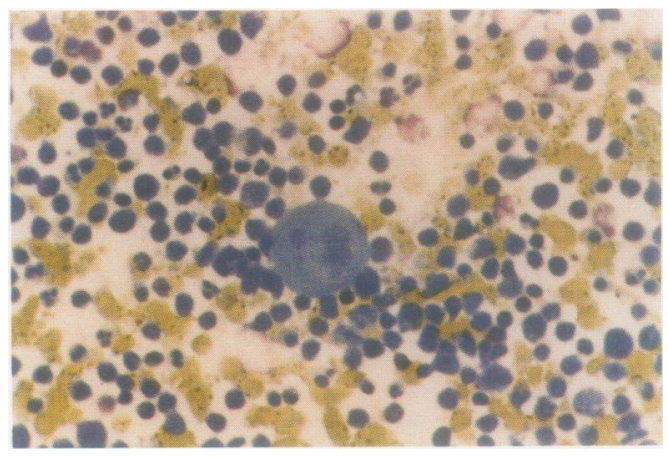

Figure 2 A Leishman stained cytospin preparation of the aspirated pericardial fluid. 
$96 \mathrm{~g} / \mathrm{l}$, white cell count of $17 \cdot 0 \times 10^{9} / 1$, and a platelet count of $70 \times 10^{9} / 1$ and did not clot.

A stained (Wright's) cytospin preparation of the pericardial fluid showed a small number of nucleated red cells, occasional megakaryocytes, and numerous myelocytes and monocytes suggesting extramedullary haemopoiesis in the pericardial space (fig 2). Chemotherapy was started with etoposide $100 \mathrm{mg} / \mathrm{m}^{2}$ intravenously, days $1-3$, cytosine arabinoside $150 \mathrm{mg}$ twice daily intravenously for five days, and prednisolone $40 \mathrm{mg}$ daily by mouth.

Treatment was well tolerated with a good clinical and haematological response. Repeat echocardiographs showed no recurrence of the pericardial effusion. Continuous oral etoposide was prescribed for the next three months.

Five months after the initial presentation he was readmitted to hospital with tense ascites. Pronunced hepatosplenomegaly with abdominal lymphadenopathy was evident on a computed tomogram. A cytospin of the ascitic fluid showed $0.1 \times 10^{9}$ cells $/$, all of which were mature monocytes. Five days of intravenous cytosine arabinoside was given $\left(100 \mathrm{mg} / \mathrm{m}^{2}\right.$ twice a day) with a good initial response. The ascites returned within four weeks. Paracentesis, intraperitoneal bleomycin, and chemotherapy with hydroxyurea all failed to give other than short term control. A third course of cytosine arabinoside and etoposide were given without response and his condition deteriorated. He died 10 months after presentation.

\section{Discussion}

Ascites and effusions affecting the pleural and pericardial spaces have previously been described in patients in CMML. ${ }^{346}$ These have all been serous effusions usually containing monocytes.

The unusual features of the pericardial effusion in this case were the cytological characteristics of the pericardial fluid, suggesting extramedullary haemopoeisis.

A computed tomogram performed after pericardiocentesis showed enlarged superior mediastinal lymph nodes with pericardial thickening. Lymphadenopathy is well recognised in CMML, ${ }^{24}$ and may be due to infiltration by monocytes ${ }^{6}$ or a concomitant lymphoproliferative disorder. ${ }^{7}$ More recently, extramedullary haemopoiesis has been described as a cause of mediastinal lymphadenopathy in CMML. ${ }^{8}$
The echocardiogram in this case showed evidence of pericardial and epicardial infiltration, and when taken with the cytospin findings, suggests that both the pericardium and epicardium were sites of extramedullary haemopoiesis leading to the development of the effusion.

CMML is a heterogenous disorder. Studies examining prognostic factors in CMML have identified the importance of a high peripheral blood monocyte count at presentation ${ }^{3}$ and an increase in blood or bone marrow blast cells. $^{39}$ The modified Bournemouth score would not have identified this patient as belonging to a poor prognosis group at presentation, but the monocyte count at presentation was $4.6 \times 10^{9} / 1$, and a concentration of $>2.6 \times 10^{9} / 1$ may identify a poor prognosis group of patients with a median survival of just 11 months. ${ }^{10}$

Both the pericardial effusion and serous ascites occurred when the monocyte count was rapidly rising. Contrary to the experience reported by Mufti et $a l,{ }^{4}$ the ascites was particularly resistant to treatment.

We believe this to be the first description of cardiac tamponade in CMML associated with extramedullary haemopoiesis affecting the pericardium. Effusions in CMML occur more frequently in patients with high or rising monocyte counts, and may identify a subgroup of patients with a poor prognosis.

1 Bennet JM, Catovsky D, Daniel MT, et al. (FAB Cooperative Group). Proposals for the classification of the myelodysplastic syndromes. $\mathrm{Br} F$ Haematol 1982;51: 189-9.

2 Foucar K, Langdon RM, Armitage JO, Olson D, Carroll TJ. Myelodysplastic syndromes. A clinical and pathological analysis of 109 cases. Cancer 1985;56:553-61.

3 Fenaux P, Jouet JP, Zandecki $M$, et al. Chronic and subacute myelomonocytic leukaemia in the adult: a report of 60 cases with special reference to prognostic features. $\mathrm{Br}$ f Haematol 1987;65:101-6.

4 Mufti GJ, Oscier DG, Hamblin TJ, Nightingale A, Darlow S. Serous effusions in monocytic leukaemia. $B r$ Darlow S. Serous effusions in

5 Duguid JKM, MacKie MJ, McVerry BA. Skin infiltration associated with chronic myelomonocytic leukaemia. $\mathrm{Br}$ f Haematol 1983;53:257-64.

6 Manoharan A. Malignant pleural effusion in chronic myelomonocytic leukaemia. Thorax 1991;46:461-2.

7 Manoharan A, Catovsky D, Clein P, et al. Simultaneous or spontaneous occurrence of lymph- and myeloproliferative disorders. Aspects of four cases. $\mathrm{Br} \mathcal{F}$ Haematol 1981;48:111-16.

8 Hunter AE, Russell NH, Ellis I. Extramedullary haemopoeisis as a cause of mediastinal lymphadenopathy in chronic myelomonocytic leukaemia. Clin Lab Haematol 1990;12:465-9.
Alessandrino EP, Ovlandi E, Brusamolini E, et al. Chronic Alessandrino EP, Ovlandi E, Brusamolini E, et al. Chronic
myelomonocytic leukaemia; clinical features, cytogenetics and prognosis in 30 consecutive cases. Haematol Oncol 1985;3:147-55.

10 Worsley A, Oscier DG, Stevens J, et al. Prognostic features of chronic myelomonocytic leukaemia: a modified Bournemouth Score gives the best prediction of survival. Br f Haematol 1988;68:17-21. 